13,14

\title{
Структурные свойства тонких пленок, полученных магнетронным распылением полидиацетилена
}

\author{
() О.А. Стрелецкий ${ }^{1}$, И.А. Завидовский ${ }^{1,}$, О.Ю. Нищак ${ }^{1}$, А.Н. Щеголихин ${ }^{2}$, Н.Ф. Савченко ${ }^{1}$ \\ ${ }^{1}$ Московский государственный университет им. М.В. Ломоносова, \\ Москва, Россия \\ ${ }^{2}$ Институт биохимической физики им. Н.М. Эмануэля РАН, \\ Москва, Россия \\ IE-mail: ia.zavidovskii@physics.msu.ru
}

Поступила в Редакцию 21 мая 2020 г.

В окончательной редакции 12 июня 2020 г.

Принята к публикации 14 июня 2020 г.

Изучались пленки, полученные высокочастотным распылением монокристаллического полидиацетилена (ПДА). Исследование структуры проводилось методами спектроскопии комбинационного рассеяния, просвечивающей электронной микроскопии и рентгеновской фотоэлектронной спектроскопии. Показано, что полученные пленки имеют гетерогенную структуру, содержащую агломераты наноразмерных включений исходного ПДА и нерегулярные $s p / s p^{2}$-гибридизованные фрагменты углеродных цепей.

Ключевые слова: полидиацетилен, магнетронное распыление, просвечивающая электронная микроскопия, КР-спектроскопия, рентгеновская фотоэлектронная спектроскопия.

DOI: 10.21883/FTT.2020.11.50073.113

\section{1. Введение}

Наноструктурированные материалы, изготовленные путем внедрения в матрицу тонкой пленки наноразмерных частиц, в настоящее время являются предметом исследования многих научных групп [1-5].

Включение в материал наночастиц позволяет в значительной степени модифицировать свойства структуры. В подобных материалах могут проявляться такие эффекты, как конфайнмент, квантово-размерный эффект Штарка, усиленное поверхностью комбинационное рассеяние и т.д. [6-8]. Материалы с внедренными нанокластерами могут применяться в качестве функциональных покрытий, элементов наноэлектроники, биосенсоров, активных оптических сред и др. [9-11].

Особенный интерес представляет изучение тонкопленочных структур с полимерными включениями. Однако существующие способы синтеза таких пленок могут быть достаточно сложны [12-14]. Поэтому перспективы их применения связаны с исследованием возможности создания материалов, содержащих полимерные нанокластеры, при помощи распространенных и универсальных технологий нанесения тонкопленочных покрытий, одной из которых является магнетронное распыление.

Изучением пленок, изготовленных при помощи магнетронного распыления полимерных мишеней, занимались в работах [15-17]. При этом выбор полимеров определялся перспективой создания покрытий с заданными свойствами. Так, перенос политетрафторэтилена (тефлона) $[15,16]$ позволил синтезировать гидрофобные покрытия, а пленки, полученные распылением полиимида, показали хорошие трибологические и прочностные характеристики $[17,18]$.
В настоящей работе распыляемым полимером служил монокристаллический полидиацетилен (ПДА). Использовавшийся для распыления тип ПДА известен в литературе под аббревиатурой PTS [19]. Монокристаллы данного материала построены из одинаково ориентированных полимерных цепей, имеющих квазиодномерный углеродный скелет, состоящий из $\pi$-сопряженных чередующихся $\mathrm{C} \equiv \mathrm{C}-, \mathrm{C}=\mathrm{C}$ - и $\mathrm{C}-\mathrm{C}$-связей. Получаемые в результате твердофазной топохимической полимеризации (ТТП) полидиацетилены проявляют ряд уникальных свойств, таких как термохромизм, пьезохромизм, сольватохромизм, аффинохромизм, и обладают выдающимися нелинейными оптическими свойствами, а также высокой анизотропией оптических, механических, электрофизических и др. свойств. Поэтому диацетилен и ПДА являются объектом интенсивных исследований, направленных как на практическое использование этих материалов (например, в биосенсорах, в устройствах сверхбыстрой оптической обработки сигналов, при создании фотонных кристаллов и проч.), так и на решение фундаментальных проблем, например, в нелинейной оптике, физике квазиодномерных полисопряженных систем, супрамолекулярной химии или в теории твердофазных химических реакций [20]. Пленки, содержащие полидиацетиленовые включения, имеют перспективы применения в различных наносенсорах. Однако структура покрытий нуждается в детальном анализе, так как зависит не только от распыляемого полимера, но и от условий синтеза [15-17]. В нашей работе для исследования образцов использовались методы спектроскопии комбинационного рассеяния (КР-спектроскопии), просвечивающей электронной микроскопии (ПЭМ) и рентгеновской фотоэлектронной спектроскопии (РФЭС). 
<smiles>Cc1ccc(S(=O)(=O)OCC#CC#CCOS(=O)(=O)c2ccc(C)cc2)cc1</smiles>

Pис. 1. Структура мономера PTS.

\section{2. Получение образцов и методы их исследования}

\section{1. Методика получения образцов}

2.1.1. Синтез мономера бис-п-толилсульфоната гекса2.4-диин-1,6-диола (PTS). В $100 \mathrm{ml}$ тетрагидрофурана растворяли $11 \mathrm{~g}(0.1 \mathrm{~mol})$ гекса-2,4-диин-1,6-диола и $50 \mathrm{~g}$ тозилхлорида (хлорангидрид п-толуолсульфо-кислоты). Полученный раствор охлаждали на бане с ледяной водой и при интенсивном перемешивании осторожно прибавляли к нему по каплям раствор $10 \mathrm{~g} \mathrm{KOH} \mathrm{в} 40 \mathrm{ml}$ воды, удерживая температуру реакционной смеси в интервале $10-15^{\circ} \mathrm{C}$. Реакционную смесь перемешивали еще $2 \mathrm{~h}$, а затем выливали разом в $1000 \mathrm{ml}$ ледяной воды. Целевой продукт немедленно выпадал в осадок в виде мелких кристаллов. Осадок отделяли фильтрованием и несколько раз промывали на фильтре большим количеством ледяной воды. Выход продукта составлял в разных синтезах 95-98\%. Полученный таким образом мономер, представленный на рис. 1, дважды очищали перекристаллизацией из горячего раствора метанол/вода (95/5), предохраняя получаемые кристаллы от воздействия света. Чистый мономер представляет собой бесцветные кристаллы, имеющие температуру плавления $96^{\circ} \mathrm{C}$ и обладающие высокой чувствительностью к действию света или тепла.

2.1.2. Получение монокристаллов ПДА. ТПП мономерных кристаллов осуществляли термическим методом, нагревая кристаллы в термостатируемом шкафу при $70^{\circ} \mathrm{C}$ в течение 5-6h. Как было показано ранее [19], эти условия гарантировали $100 \%$-ную степень конверсии мономера PTS (рис. 2,a) в полимер (рис. 2,b). В результате получали монокристаллы поли-РTS, имеющие металлический блеск с золотым отливом.

2.1.3. Исследуемые пленки были синтезированы методом высокочастотного магнетронного распыления монокристаллов ПДА, равномерно размещенных на поверхности стандартной магнетронной мишени, изготовленной из графита марки МПГ-7, диаметр которой составлял $76 \mathrm{~mm}$. Кристаллы закрепляли на поверхности мишени при помощи углеродного скотча фирмы Carl Zeiss. Размеры монокристаллов ПДА составляли порядка $1 \mathrm{~mm}$, а доля занимаемой ими площади мишени - порядка $5 \%$.

Предварительная откачка (до $5 \cdot 10^{-5}$ Torr) вакуумной камеры, в которой производилось напыление, осуществлялась при помощи вакуумной системы, состоящей из пластинчатороторного и турбомолекулярного насоса.

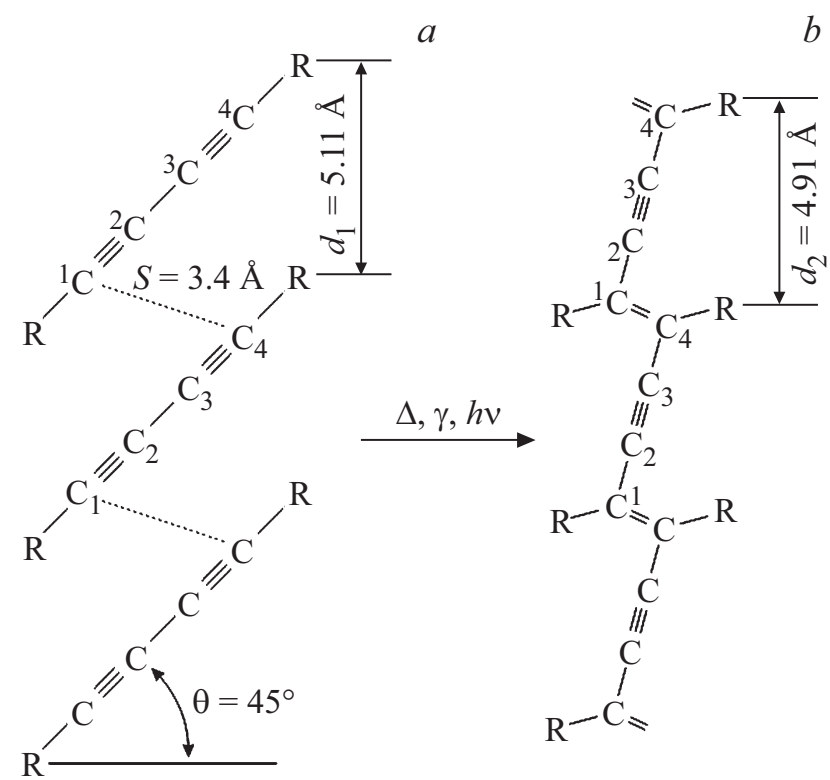

Рис. 2. Параметры кристаллической упаковки и молекулярная структура мономера PTS $(a)$ и соответствующего полимера PTS $(b)$, использованного в настоящей работе.

После откачки в камеру напускался рабочий газ аргон $(\mathrm{Ar})$. Рабочее давление составляло $9 \cdot 10^{-4}$ Torr.

Напыление проводилось при мощности разряда $50 \mathrm{~W}$. При данной мощности скорость распыления полимера значительно превышала скорость распыления графитовой мишени, на которой были закреплены кристаллы ПДА. Благодаря этому структура пленки, исследуемой в настоящей работе, преимущественно определялась распылением ПДА. В качестве подложек были использованы монокристаллический полированный $\mathrm{Si}$ и скол $\mathrm{NaCl}$. Время распыления подбиралось таким образом, чтобы толщина изготовленных образцов составляла приблизительно $100 \mathrm{~nm}$. Контроль толщины во время процесса напыления осуществлялся при помощи пьезоэлектрического датчика.

\section{2. Методы исследования образцов}

Исследования с помощью просвечивающей электронной микроскопии проводились на базе просвечивающего электронного микроскопа LEO $912 \mathrm{ab}$ с ускоряющим напряжением $120 \mathrm{keV}$.

Спектры комбинационного рассеяния регистрировали с помощью КР-спектрометра RamanStation-400 (PerkinElmer, USA), оснащенного 30-кратным микроскопом, 

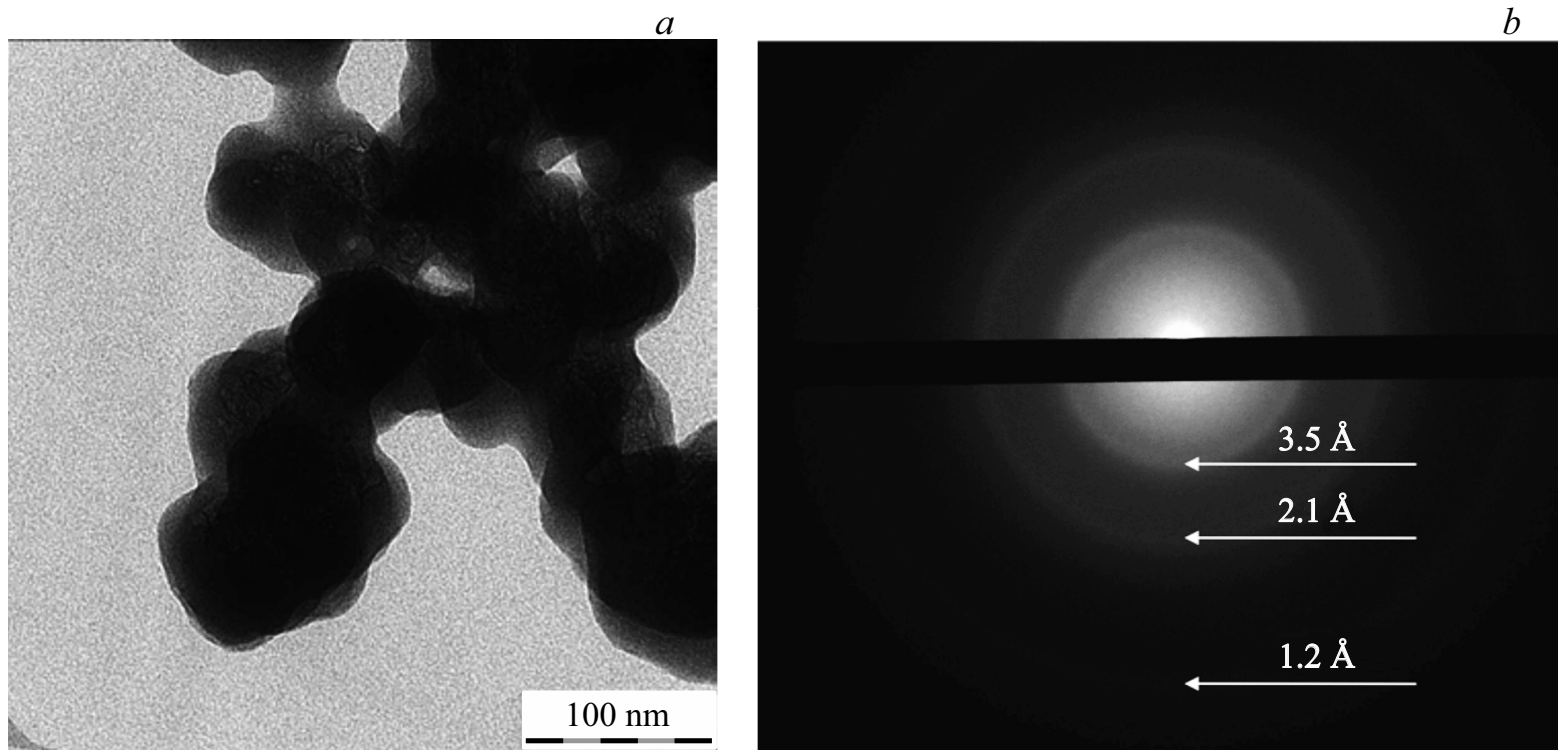

Рис. 3. ПЭМ-изображение пленки на основе полидиацетилена с агломератами наноразмерных включений (a). Характерная дифракция исследуемой пленки $(b)$.

моторизованным $X Y Z$-координатным столиком и лазерным возбуждением $785 \mathrm{~nm}$. Спектры записывали без подготовки пробы для анализа при оптическом разрешении $1 \mathrm{~cm}^{-1}$, помещая исследуемый образец под объектив прибора. Спектры записывали при мощности лазерного возбуждения 2-10 $\mathrm{mW}$, аккумулируя и усредняя 25-100 сканов с длительностью экспонирования детектора $10-30 \mathrm{~s}$.

РФЭС осуществлялась с помощью электронного спектрометра Kratos AXIS Ultra DLD. Рентгеновское излучение в спектрометре обеспечивалось источником с магниевым анодом с энергией, соответствующей дублету $\mathrm{Al} K_{\alpha}=1486.6 \mathrm{eV}$.

\section{3. Экспериментальные результаты}

\section{1. ПЭМ}

По данным ПЭМ, в структуре пленки наблюдается значительное число включений, представляющих собой агломераты наноразмерных частиц (см. рис. 3,a). Обработка изображений, полученных с помощью ПЭМ, показала, что относительная площадь включений составляет 4.3\%. На рис. $3, b$ приведена дифракционная картина, характерная для исследованного образца.

На данной дифрактограмме присутствуют пики с центрами, соответствующими малым межплоскостным расстояниям: 1.2 и $2.1 \AA$, которые связаны с наличием аморфной фазы углерода в структуре тонкой пленки [22,23]. Пик, отвечающий межплоскостному расстоянию $3.5 \AA$, свидетельствует о присутствии в структуре графитовой составляющей [24]. В свою очередь, линии, отвечающие структуре ПДА, не удалось обнаружить по результатам электронной дифракции. Это может быть связано с тем, что для полидиацетилена характерны большие межплоскостные расстояния [25], рефлексы которых могут перекрываться фоном рассеянных электронов. Также возможно повреждение полимера пучком электронов в ходе анализа. Известно, что для ПДА даже небольшие дозы электронного облучения приводят к образованию сшивок между цепочками и изменению структуры [26].

Неустойчивость полидиацетилена к облучению электронным пучком приводит к необходимости использовать для анализа образцов другие методы. В настоящей работе дальнейшее исследование структур было проведено методами КР-спектроскопии и РФЭС.

\section{2. КР-спектроскопия}

На рис. 4 представлены КР-спектры пленки, полученной при распылении полидиацетилена, а также исход-

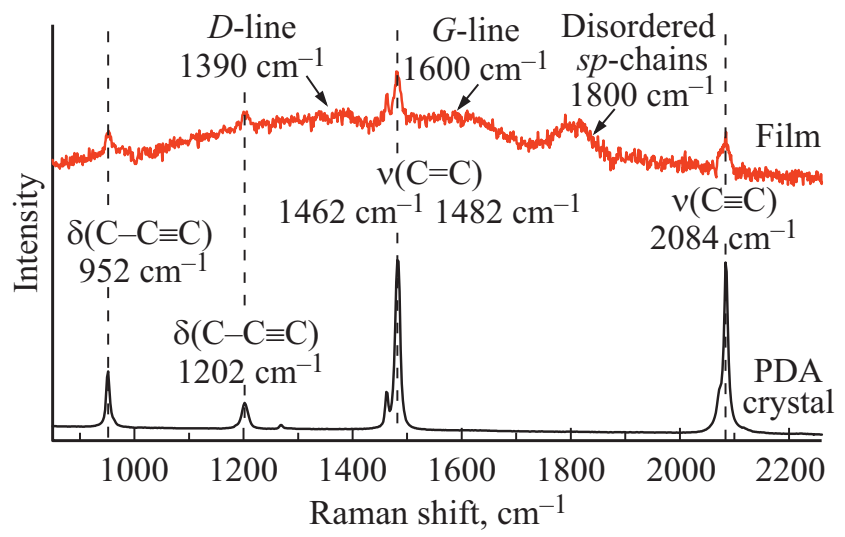

Рис. 4. КР-спектры монокристалла ПДА и пленки. 
ного материала мишени, т. е. монокристаллов ПДА PTS. Спектр мишени характерен для типичного монокристаллического ПДА [19]. Почти все линии, наблюдаемые в обоих спектрах, принадлежат колебаниям различных молекулярных фрагментов из состава сопряженного углеродного скелета макромолекулы ПДА: так, линия $952 \mathrm{~cm}^{-1}$ отвечает деформационным колебаниям $\delta(\mathrm{C}-\mathrm{C} \equiv \mathrm{C})$, полоса $1202 \mathrm{~cm}^{-1}$ соответствует деформационным колебаниям $\delta(\mathrm{C}-\mathrm{C}=\mathrm{C})$, полоса $1462 \mathrm{~cm}^{-1}$ вызвана деформационным колебанием $\delta\left(\mathrm{CH}_{2}-\mathrm{C}=\right)$, а интенсивная линия $1482 \mathrm{~cm}^{-1}$ - валентным колебанием $v(\mathrm{C}=\mathrm{C})$, и, наконец, интенсивная полоса $2084 \mathrm{~cm}^{-1}$ принадлежит валентному колебанию тройной связи из состава углеродного скелета $v(\mathrm{C} \equiv \mathrm{C})$.

Примечательно, что частоты большинства КР-полос в спектре напыленной пленки наблюдаются фактически при тех же частотах, которые характерны для кристаллической ПДА-мишени. Однако известно, что частота линий КР в спектре ПДА сильно зависит от степени сохранности кристаллической элементарной ячейки ПДА или степени ее деформированности под действием внешних или внутренних напряжений и других факторов. Таким образом, сохранение положений линий КР в данном случае может служить веским аргументом в пользу того, что при высокочастотном магнетронном напылении перенос фрагментов ПДА фазы из объема мишени в пленку может происходить без значительного разрушения материнской кристаллической решетки исходного ПДА (мишени). Другими словами, входящие в состав напыляемой пленки включения функционального полимера лишь незначительно отличаются по структуре от исходного полимера.

Помимо линий, соответствующих структуре исходного ПДА, в КР-спектрах напыленной пленки наблюдается широкая полоса с вершиной вблизи $1800 \mathrm{~cm}^{-1}$, что не характерно для исходного ПДА, обладающего совершенной кристаллической структурой. Анализ литературы показывает, что подобная линия встречается в спектрах структур, содержащих цепочечную углеродную фазу, например, в КР-спектрах $s p$-гибридизованных углеродных цепочек, внедренных в многостенные нанотрубки [27], или в кумуленовой форме аморфного карбина, отожженного под высоким давлением [28]. В работе [29] серия линий с волновыми числами в диапазоне $1700-2200 \mathrm{~cm}^{-1}$ приписывается колебаниям $s p$-гибридизованных цепочек в структуре углеродсеребряных композитов. В то же время, данная линия не встречается в спектрах углеродных цепочек с $s p$-гибридизацией, находящихся в растворе [30,31], и не предсказывается моделями, в которых рассчитывается спектр идеальных цепочечных структур, стабилизированных различными радикалами [32]. Все это позволяет предположить ее связь с деформацией структуры цепочек. Данное предположение подтверждается расчетами спектра фононных колебаний цепочки с изгибами в гармоническом приближении [33]. Этот вывод находится в соответствии с результатами, представленными в [30].
Присутствие в спектре напыленной пленки фона люминесценции свидетельствует о наличии разупорядоченной фазы в структуре образца. Это также подтверждается наличием в спектре КР широких полос вблизи 1380 и $1600 \mathrm{~cm}^{-1}$, соответствующих $D$ - и $G$-линиям, положение и ширина которых характерны для разупорядоченного углерода $[34,35]$.

\section{3. РФЭС}

В таблице представлены результаты анализа элементного состава кристалла ПДА и напыленной пленки методом РФЭС. Данные элементного анализа свидетельствуют о том, что в синтезированных структурах доля углерода увеличивается по сравнению с исходным кристаллом ПДА, при этом уменьшается доля серы. Это свидетельствует о том, что в процессе переноса структуры происходит небольшое уменьшение количества стабилизирующих радикалов (так называемых боковых заместителей ПДА). Присутствие кислорода связано как с наличием данного элемента в составе тозильной группировки, так и с формированием на поверхности образца адсорбированного слоя. В свою очередь, присутствие азота и незначительной доли других примесей также может объясняться наличием адсорбатов на поверхности. Значительное влияние поверхностного слоя на РФЭС-спектр обусловлено малой глубиной анализа, составляющей 0.5-3 nm [36].

На рис. 5, a представлен спектр C1s линии для кристалла ПДА. Вычитание фона производилось методом Тугарда [37], на рисунке фон представлен пунктиром. Во вкладке приведено разложение C1s по двум гауссовым составляющим, отвечающим химическим связям углерода. Пик с энергией $284.3 \mathrm{eV}$ соответствует $\mathrm{C}-\mathrm{C}$-связям $[38,39]$. В свою очередь, линии, отвечающие $\mathrm{C}-\mathrm{O}-, \mathrm{C}-\mathrm{N}-, \mathrm{C}-\mathrm{S}-$ связям, имеют схожее положение около $286.5 \mathrm{eV}$ [3,40-43]. Наложение данных линий приводит к большой ширине соответствующего им пика и не позволяет разрешить их по отдельности. Аналогичное разложение проводилось для спектра 1s-линии напыленной пленки.

При вычитании линий химических связей из спектров 1s-линий были получены спектры потерь энергии электронов, представленные на рис. $5, b$. На данном рисунке ноль энергии отсчитывается от положения максимума C1s-линии. В данном спектре присутствуют пики потерь энергии, связанные с возбуждениями плазмонов в исследуемом материале, а также одноэлектронными переходами.

Пик с энергией $3.8-4.1 \mathrm{eV}$ соответствует возбуждению $\pi$-плазмонов в углеродных цепочках [44]. Присутствие данной линии в спектре исходного кристалла

Элементный состав кристалла ПДА и напыленной пленки

\begin{tabular}{c|c|c|c|c|c}
\hline & C 1s & O 1s & S 2p & N 1s & Other \\
\hline PDA-crystal & 74.49 & 18.95 & 4.21 & 2.04 & 0.32 \\
Film & 78.87 & 14.88 & 2.92 & 2.80 & 0.53
\end{tabular}



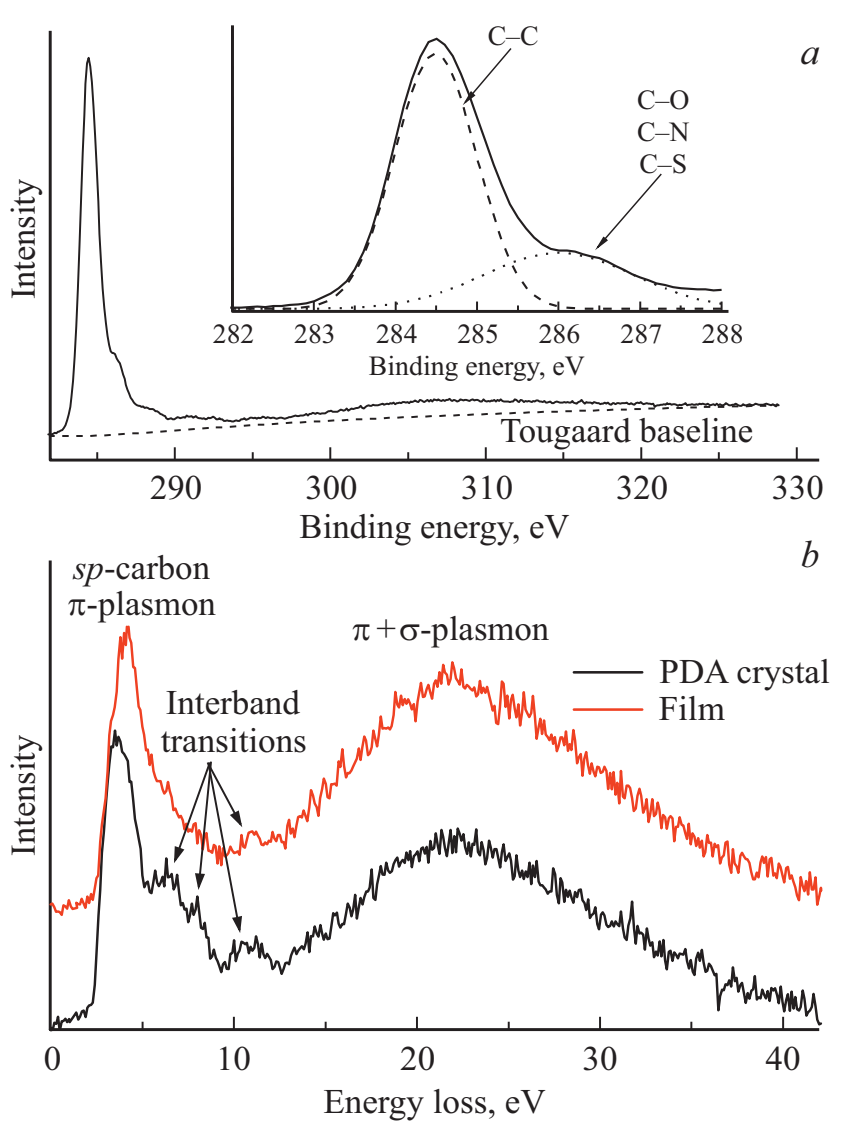

Pис. 5. C1s-линия кристалла ПДА. Во вкладке представлено разложение спектра по линиям химических связей $(a)$. Спектры потерь энергии электронов в ПДА и материале пленки $(b)$.

связано с формированием в ПДА цепочек на основе $s p$-связи. $\pi$-плазмон в спектре напыленной пленки отвечает возбуждению колебаний как во фрагментах, имеющих структуру исходного полимера, так и в искаженных углеродных цепочках.

Пик с энергией $22 \mathrm{eV}$ отвечает коллективному возбуждению всей электронной подсистемы $(\pi+\sigma)$. Положение данного пика позволяет оценить плотность материала [45]. Согласно проведенной оценке, плотность ПДА и напыленной пленки приблизительно одинаковы и составляют около $1.5 \mathrm{~g} / \mathrm{cm}^{3}$.

Кроме того, в спектрах наблюдаются три пика с энергиями $6.5,8$ и $11 \mathrm{eV}$, которые соответствуют одночастичным межзонным переходам [46], связанным со сложной зонной структурой кристалла полидиацетилена. В свою очередь, для аморфных углеродных структур в спектрах потерь, как правило, наблюдается небольшое число межзонных переходов меньшей интенсивности [47]. Таким образом, уменьшение интенсивности и количества линий в диапазоне 5-13 eV можно связать с разупорядочением структуры покрытия.

Согласно полученным результатам, напыленная пленка представляет собой аморфную углеродную матрицу, содержащую агломераты наноразмерных включений кристаллического ПДА наряду с включениями искажен- ных цепочечных фрагментов, структура которых сформировалась во время переноса материала мишени на подложку.

\section{4. Обсуждение результатов}

Как правило, формирование полимерной структуры при магнетронном распылении происходит благодаря переносу малых фрагментов материала мишени, которые либо вступают в химическую реакцию на поверхности формируемой пленки, либо взаимодействуют в плазме, если давление в рабочей камере достаточно велико ( 50 Torr) $[15,16,48,49]$. В нашем случае длина свободного пробега распыляемых фрагментов оказывается слишком велика для их взаимодействия в плазме, поскольку рабочее давление составляло $10^{-3}$ Torr. Кроме того, при распылении происходит разрушение структуры стабилизаторов (боковых заместителей скелета ПДА). Например, в процессе магнетронного распылениия может повреждаться структура бензольных колец [50]. Таким образом, перенос материала в наших условиях происходит небольшими фрагментами, из которых на поверхности растущей пленки формируется новая структура. Синтезируемые в схожих условиях при ВЧ-распылении полимеров покрытия, как правило, обладают разупорядоченной структурой $[15,48]$. Вследствие этого можно предположить, что появление в структуре напыленной пленки деформированных цепочек, о котором свидетельствует широкая линия $1800 \mathrm{~cm}^{-1}$ в КР-спектрах, связано именно с взаимодействием небольших квазиодномерных фрагментов полимера на поверхности растущей пленки.

Однако положения большинства линий в КР-спектре пленки практически не отличаются от таковых для кристалла ПДА. Это свидетельствует о том, что полимерные включения в пленке достаточно упорядочены, а их структура практически не отличается от структуры исходного кристалла, что нехарактерно для магнетронного распыления. По нашему предположению, перенос полимера также может осуществляться благодаря испарению материала мишени, связанному с локальным нагревом кристаллов ПДА. Нагрев вызывается воздействием ионного потока, бомбардирующего мишень при магнетронном распылении. Схожий эффект описан в [51]. Для его реализации в случае металлических мишеней поток тепла уменьшают, изолируя их от охлаждаемых магнитов магнетронной системы. В нашем случае теплоотвод от закрепленных на мишени кристаллов ПДА происходил неэффективно из-за их низкой теплопроводности [52]. Согласно литературным данным, испарение различных полимеров приводит к формированию высокоупорядоченных покрытий на основе исходного материала [53-55].

Таким образом, сочетание испарения и распылении при магнетронном осаждении может позволить создавать композитные структуры, представляющие собой аморфную углеродную матрицу, содержащие наноразмерные полимерные включения, повторяющие структуру распыляемого материала. 


\section{5. Заключение}

В работе представлены результаты исследования пленок, полученных высокочастотным магнетронным распылением мишени, содержащей кристаллы ПДА. Согласно данным ПЭМ, пленки представляют собой аморфную углеродную матрицу с агломератами наноразмерных включений. Присутствие $D$ - и $G$-линий в КР-спектрах подтверждает формирование аморфной углеродной фазы в структуре пленки. Наличие в КР-спектре пленки линий, соответствующих колебаниям исходного кристалла ПДА, свидетельствует о переносе фрагментов структуры полимера в пленку. Появление линии $1800 \mathrm{~cm}^{-1}$ указывает на формирование фрагментов на основе искаженных $s p$-гибридизованных углеродных цепочек. Наличие $\pi$-плазмона с положением около $4 \mathrm{eV}$ в спектрах потерь энергии рентгеновских фотоэлектронов подтверждает наличие структуры на основе $s p$-гибридизации: искаженных углеродных цепочек и полидиацетиленовых фрагментов. Согласно нашему предположению, формирование искаженных $s p$-гибридизованных цепочек происходит на поверхности растущей пленки из небольших распыленных $s p$-гибридизованных кластеров исходного ПДА. В свою очередь, перенос полимерных фрагментов, структура которых незначительно отличается от структуры ПДА, связан с испарением вследствие локального нагрева кристаллов, расположенных на поверхности магнетронной мишени.

\section{Благодарности}

Авторы выражают благодарность за обсуждение результатов В.В. Хвостову.

\section{Конфликт интересов}

Авторы заявляют, что у них нет конфликта интересов.

\section{Список литературы}

[1] А.В. Елопов, В.Б. Зайцев, Д.М. Жигунов, Г.А. Шандрюк, А.А. Ежов, А.С. Мерекалов, Л.А. Головань. Изв. РАН. Сер. физ. 83, 41 (2019).

[2] В.А. Данько, С.А. Злобин, И.З. Индутный, И. П. Лисовский, В.Г. Литовченко, Е.В. Михайловская, П.Е. Шепелявый, Е. Бегун. Материалы электрон. техники 4, 52 (2013).

[3] O.A. Streletskiy, I.A. Zavidovskiy, O.Yu. Nischak, A.A. Haidarov. Vacuum 175, 109286 (2020).

[4] А.В. Колубаев, А.В. Белый, И.А. Буяновский, Е.А. Колубаев, В.А. Кукареко, О.В. Сизова, М.М. Хрущов. Изв. вузов 62, 8, 52 (2019).

[5] М.М. Хрущов, М.В. Атаманов, Е.А. Марченко, М.И. Петржик, И.С. Левин. Изв. РАН. Сер. физ. 78, 10, 1257 (2014).

[6] Q. Cheng, S. Xu, K. Ostrikov. Acta Mater. 58, 560 (2010).

[7] D. Babić, R. Tsu, R.F. Greene. Phys. Rev. B 45, 14150 (1992).

[8] V. Türck, S. Rodt, O. Stier, R. Heitz, R. Engelhardt, U.W. Pohl, D. Bimberg, R. Steingrüber. Phys. Rev. B 61, 15, 9944 (2000).
[9] M. Fu, F. Ehrat, Yu Wang, K.Z. Milowska, C. Reckmeier, A.L. Rogach, J.K. Stolarczyk, A.S. Urban, J. Feldmann. Nano Lett. 15, 6030 (2015).

[10] H. Mertens, J.S. Biteen, H.A. Atwater, A. Polman. Nano lett. 6, 2262 (2006).

[11] С.Н. Штыков, Т.Ю. Русанова. Рос. хим. журн. LII, 92 (2008)

[12] E. Palesch, A. Marek, P. Solarc, O. Kylian, J. Vyskocil, H. Biederman, V. Cech. Thin Solid Films 544, 593 (2013).

[13] P. Solař, O. Polonskyi, A. Choukourov, A. Artemenko, J. Hanuš, H. Biederman, D.Slavínská. Surf. Coatings Technol. 205, S42 (2011).

[14] J.C. Tuberquia, G.K. Jennings. ACS Appl. Mater. Interfaces 5, 7, 2593 (2013).

[15] H. Biederman, P. Bílková, J. Ježek, P. Hlídek, D. Slavínská. J. Non-Crystal. Solids 218, 44 (1997).

[16] M. Drabik, O. Polonskyi, O. Kylian, J. Cechvala, A. Artemenko, I. Gordeev, A. Choukourov, D. Slavınska, I. Matolınova, H. Biederman. Plasma Proc. Polymers 7, 7, 544 (2010).

[17] A. Choukourov, J. Hanuš, J. Kousal, A. Grinevich, Y. Pihosh, D. Slavínská, H. Biederman. Vacuum 81, 4, 517 (2006).

[18] M. Kitoh, Y. Honda. Thin Solid Films 271, 1-2, 92 (1995).

[19] A.N. Shchegolikhin, O.L. Lazareva. Spectrochim. Acta A 53, 1, 67 (1997).

[20] R. Baughman, D. Galvão, C. Cui, S. Dantas. Chem. Phys. Lett. 269, 3-4, 356 (1997).

[21] Г.А. Виноградов. Успехи химии 53, 1, 135 (1984).

[22] A.A. Voevodin, J.G. Jones, J.S. Zabinski, Zs. Czigány, L. Hultman. J. Appl. Phys. 92, 4980 (2002).

[23] M. Zarrabian, N. Fourches-Coulon, G. Turban, C. Marhic, M. Lancin. Appl. Phys. Lett. 70, 2535 (1997).

[24] H. Song, L. Ji, H. Li, X. Liu, W. Wang, H. Zhou, J. Chen. ACS Appl. Mater. Interfaces 8, 6639 (2016).

[25] R.J. Young, R.T. Read, D. Bloor, D. Ando. Faraday Discus. Chem. Soc. 68, 509 (1979).

[26] R.T. Read, R.J. Young. J. Mater Sci. 19, 1, 327 (1984).

[27] X. Zhao, Y. Ando, Y. Liu, M. Jinno, T. Suzuki. Phys. Rev. Lett. 90, 18, 187401-1 (2003).

[28] Т.Д. Варфоломеева, С.В. Попова, А.Г. Ляпин, С.Г. Ляпин, В.В. Бражкин, Ю.П. Кудрявцев, С.Е. Евсюков. Письма в ЖЭТФ 66, 237 (1997).

[29] A. Jurkevičiūtè, G. Klimaite, T. Tamulevičius, J. Fiutowski, H. Rubahn, S. Tamulevičius. Adv. Eng. Mater. 22, 1900951 (2019).

[30] H. Tabata, M. Fujii, S. Hayashi, T. Doi, T. Wakabayashi. Carbon 44, 15, 3168 (2006).

[31] B. Pan, J. Xiao, J. Li, P. Liu, C. Wang, G. Yang. Sci. Adv. 1, 9, e1500857 (2015).

[32] R.R. Tykwinski. Chem. Record 15, 6, 1060 (2015).

[33] F. Cataldo. Polyynes: Synthesis, Properties, and Applications. CRC Press (2005). P. 233.

[34] A.C. Ferrari, J. Robertson. Phys. Rev. B 61, 20, 14095 (2000).

[35] J.-T. Jiu, H. Wang, C.-B. Cao, H.-S. Zhu. J. Mater. Sci. 34, 21, 5205 (1999).

[36] M.P. Seah. Vacuum 34, 463 (1984).

[37] S. Tougaard. Surf. Sci. 216, 3, 343 (1989).

[38] B.K. Tay, X. Shi, H.S. Tan, D.H.C. Chua. Surf. Interface Anal. 28, 1, 231 (1999).

[39] R.G. Lacerda, P. Hammer, F.L. Freire, F. Alvarez, F.C. Marques. Diamond Rel.Mater. 9, 3-6, 796 (2000). 
[40] G. Sobon, J. Sotor, J. Jagiello, R. Kozinski, M. Zdrojek, M. Holdynski, P. Paletko, J. Boguslawski, L. Lipinska, K.M. Abramski. Opt. Exp. 20, 19463 (2012).

[41] R.N. Oosterbeek, C.K. Seal, M.M. Hyland. Appl. Surf. Sci. 321, 432 (2014).

[42] E.T. Kang, H.C. Ti, K.G. Neoh. Polym J. 20, 845 (1988).

[43] R.K. Shervedani, A. Amini. Carbon 93, 762 (2015).

[44] Ю.Г. Коробова, В.Г. Бабаев, В.В. Хвостов, М.Б. Гусева. Вестн. Моск. ун-та. Сер. 3. Физика. Астрономия 1, 33 (2008).

[45] B. Schultrich. Tetrahedrally Bonded Amorphous Carbon Films I. Springer Berlin Heidelberg, Berlin, Heidelberg (2018). 752 p.

[46] J. Knecht, B. Reimer, H. Bassler. Chem. Phys. Lett. 49, 2, 327 (1977).

[47] И.А. Завидовский, О.А. Стрелецкий, О.Ю. Нищак, Н.Ф. Савченко, С.В. Дворяк, А.В. Павликов. ЖТФ 90, 3, 489 (2020).

[48] H. Biederman, M. Zeuner, J. Zalman, P. Bílková, D. Slavínská, V. Stelmasuk, A. Boldyreva. Thin Solid Films 392, 2, 208 (2001).

[49] I. Kholodkov, H. Biederman, D. Slavinska, A. Choukourov, M. Trchova. Vacuum 70, 4, 505 (2003).

[50] K. Fukushima, Y. Ikeda, T. Hayashi, N. Kikuchi, E. Kusano, A. Kinbara. Thin Solid Films 392, 2, 254 (2001).

[51] G.A. Bleykher, A.O. Borduleva, V.P. Krivobokov, D.V. Sidelev. Vacuum 132, 62 (2016).

[52] M.N. Wybourne, B.J. Kiff, D.N. Batchelder. Phys. Rev. Lett. 53, 6, 580 (1984).

[53] S.G. Hansen, T.E. Robitaille. Appl. Phys. Lett. 52, 1, 81 (1988).

[54] S. Tomaru, K. Kubodera, S. Zembutsu, K. Takeda, M. Hasegawa. Electron. Lett. 23, 11, 595 (1987).

[55] Y. Takahashi, M. Iijima, Y. Oishi, M. Kakimoto, Y. Imai. Macromolecules 24, 12, 3543 (1991).

Редактор К.В. Емцев 